\title{
Measurement of gas diffusion through soils: comparison of laboratory methods
}

\author{
Suzanne E. Allaire ${ }^{* a}$, Jonathan A. Lafond ${ }^{a}$, Alexandre R. Cabral ${ }^{b}$, and Sébastien F. Lange ${ }^{a}$ \\ Received (in 2008, May) 1st January 2007, Accepted 1st January 2007 \\ First published on the web 1st January 2007 \\ DOI: 10.1039/b000000x J. Env. Monitoring 10: 1326-1336.
}

Gas movement through soils is important for ecosystems and engineering in many ways such as for microbial and plant respiration, passive methane oxidation in landfill covers and oxidation of mine residues. Diffusion is one of the most important gas movement processes and the determination of the diffusion coefficient is a crucial step in any study. Five laboratory methods used for measuring the relative gas diffusion coefficient $\left(D_{s} / D_{o}\right)$ were compared using a loamy sand, a porous media commonly found in agricultural fields and in several engineered structures, such as in landfill final covers. In the absence of macropores, all methods gave rather similar values of $D_{s} / D_{o}$. Methods allowing the study of microscale variability indicated that the presence of macropores highly influenced gas movement, thus the value of $D_{s} / D_{o}$, which, near a macropore may be one order of magnitude higher than in regions without macropores. Repacked columns do not allow the study of heterogenity in $D_{s} / D_{o}$. Natural spatial variability in $D_{s} / D_{o}$ due to water distribution and preferential pathways can only be studied in large systems, but these systems are difficult to handle.

Advantages and disadvantages of each method are discussed.

\section{Introduction}

Gas movement through porous media, in particular soils, is a fundamental aspect of many environmental, engineering, ecological, agricultural and biological problems. For example, most plants and microorganisms living in top soils need atmospheric oxygen $\left(\mathrm{O}_{2}\right)$ ingress by diffusion otherwise they suffocate. Many of these microorganisms are important for the decomposition of organic matter and contaminants while others impact $\mathrm{N}$ and $\mathrm{C}$ cycles affecting greenhouse gas (GHG) emissions. Also, fugitive emissions from landfills - which are responsible for nearly $37 \%$ of all $\mathrm{CH}_{4}$ emissions in the $\mathrm{USA}^{1}$ and $25 \%$ in Canada ${ }^{2}$ - occur in part by diffusion of biogas through the cover systems. This process needs to be well understood in order to optimize passive methane $\left(\mathrm{CH}_{4}\right)$ oxidation by methanotrophic bacteria, which thrive in the aerobic zone of the cover soil ${ }^{3}$ and can oxidize between 3 to $90 \%$ of the fugitive $\mathrm{CH}_{4}$, depending on environmental conditions, ${ }^{4}$ such as nutrient availability $^{5}$ and oxygen penetration. Many chemical reactions in soils release gases or need gas to take place, such as oxidation of mine residues, which requires $\mathrm{O}_{2}$ input. Another important aspect to be considered about microbial activity in soils is that the air surrounding the microorganisms must be replaced to eliminate toxic gases and replenish $\mathrm{O}_{2}{ }^{6}$ Gas diffusion is one of the main processes responsible for gas movement in soil. $^{7}$

\footnotetext{
a Horticultural Research Center, Université Laval, 2480 Hochelaga, G1K 7P4, Québec, Canada, fax : (418) 656-7871; Tel: (418)656-2131; E-mail:suzanne.allaire@sga.ulaval.ca

${ }^{b}$ Dept. Civil Eng., Université de Sherbrooke, Sherbrooke, Qc, Canada, $J 1 K 2 R 1$
}

One fundamental step in the study of gas diffusion is the determination of the diffusion coefficient, $D_{s}\left(\mathrm{~m}^{2} \mathrm{~s}^{-1}\right)$ in the field or laboratory. Werner and co-workers ${ }^{8}$ found only three review studies ${ }^{9-11}$ that compared $D_{s}$ values determined in situ with those obtained in the laboratory. From the limited data available, they concluded that in situ and laboratory measurements are equivalent approaches for determining $D_{s}$, however, the data were not obtained with the same soils. They also concluded that studies comparing various methods at the same site are lacking and that evaluation of various methods for heterogeneous and structured media is highly needed. We are not aware of any publication that contradicts Werner and co-workers's ${ }^{8}$ conclusion. In addition, in situ methods are costly and, in most cases, do not allow the study of gas movement during winter, and have several draw backs.

Considering the lack of information about $D_{s}$ for heterogeneous soils, the fact that there is a good correlation between in situ and laboratory measurements for $D_{s}$, and the relative easiness of performing laboratory tests in comparison to field tests, the goal of this study was to compare five laboratory methods for measuring $D_{s}$ of a relatively heterogeneous loamy sand.

\section{Background}

\section{Gas diffusion process}

Gas-phase diffusion occurs due to collisions between gas molecules. In soils, adjustments to the diffusion coefficient in air are required to account for both the occupancy of a large fraction of the volume by solids or liquids and the non-linearity of the diffusion path in the gas-filled porosity. The adjustments are typically accounted for through a factor multiplied by the 
air diffusivity, since the diffusion is still dominated by collisions between gas molecules. When collisions between molecules and solids become significant, due to low pressure or very small pores, Knudsen diffusion can occur. ${ }^{12}$ Since the soil used in this study has large particles, resulting in large pores, Knudsen diffusion is assumed negligible.

Molecular gas diffusion in soils is described using the $1^{\text {st }}$ and $2^{\text {nd }}$ Fick's laws, respectively for steady state (Eq. 1) and transient (Eq. 2) conditions:

$$
\begin{gathered}
q_{d s}=-D_{s} \frac{d C_{g}}{d z} \\
\frac{\theta_{a} \partial C_{g}}{\partial t}=D_{s} \frac{\partial^{2} C_{g}}{\partial z^{2}}
\end{gathered}
$$

where $q_{d s}$ is the diffusive flux density in soil $\left(\mathrm{g} \mathrm{m}^{-2} \mathrm{~s}^{-1}\right), D_{s}$ is the diffusion coefficient $\left(\mathrm{m}^{2} \mathrm{~s}^{-1}\right), d C_{g}$ is the concentration difference between two points $\left(\mathrm{g} \mathrm{m}^{-3}\right), d \mathrm{z}$ is the distance between two points $(\mathrm{m}), \theta_{a}\left(=\Phi-\theta_{\mathrm{v}}\right)$ is the air-filled porosity $\left(\mathrm{m}^{3} \mathrm{~m}^{-3}\right), t$ is the time $(\mathrm{s}), \theta_{v}$ is the soil water content $\left(\mathrm{m}^{3} \mathrm{~m}^{-}\right.$ $\left.{ }^{3}\right), \Phi\left(=1-\rho_{\mathrm{a}} / \rho_{\mathrm{s}}\right)$ is the porosity $\left(\mathrm{m}^{3} \mathrm{~m}^{-3}\right), \rho_{a}$ is the bulk density $\left(\mathrm{Mg} \mathrm{m}^{-3}\right)$, and $\rho_{s}$ is the particle density $(\approx 2.65 \mathrm{Mg}$ $\left.\mathrm{m}^{-3}\right)$.

It is often practical to normalize $D_{s}$ by the gas diffusion in air, $D_{o}\left(\mathrm{~m}^{2} \mathrm{~s}^{-1}\right)$ taken at the same pressure and temperature. The $D_{s} / D_{o}$ ratio is lower than one because tortuosity (i.e. the presence of solid particles and liquid in the pores), is assumed constant for all gases that do not react with the soil particles, ${ }^{13}$ and depends only on the properties of the airfilled pores of the soil rather than on gas properties.

\section{Relative gas diffusion coefficient relationships}

Since measuring methods are time consuming, relationships have been developed for predicting $D_{s} / D_{o}$. The simple methods listed in Table 1 are usually chosen so that diffusion can be calculated from easily measured parameters such as $\theta_{a}$ and $\rho_{\mathrm{a}}$. The relationships vary in their approach, and are applicable to the type of materials and the range of $\theta_{v}$ used for their development. Since $D_{s}$ for a gas in the liquid phase is about 10000 times lower than in the gas phase, ${ }^{\mathbf{1 4}}$ models are usually a function of $\theta_{a}$ and $\Phi$ only.
They also vary according to the importance given to $\theta_{a}$ and $\Phi$ and in the manner that the restricting factor, which usually accounts for pore tortuosity, constrictivity, and connectivity, is calculated. ${ }^{15}$ The relationships in Table 1 are widely used in numerical simulations, but their use has some drawbacks since they are sensitive at different levels to errors in the input parameters. In addition, it seems, from the literature, that there is no obvious a priori best relationship for a soil; the choice of a relationship is thus usually supported by a few measured $D_{s} / D_{o}$ in the material of interest. To choose the right model, $D_{s} / D_{o}$ must be well measured.

\section{Measuring methods}

Different methods have been developed to measure $D_{s}$ in porous media, both in the field (Fig. 1, Table 2) and in the laboratory (Fig. 2, Table 3). Laboratory methods mainly vary in their initial and boundary conditions and the type of soil core. Also, the hypotheses used to calculate $D_{s}$ vary between them. ${ }^{30}$ During measurements in the laboratory, it is usually assumed that only molecular diffusion occurs, i.e. considering Knudsen diffusion, bubbling, and convection to be negligible.

Fig.1 Scheme of selected field methods for estimating gas diffusion coefficient.

\section{Experimental study}

Five laboratory methods for measuring $D_{s} / D_{o}$ were compared (Fig. 2, Table 3): (1) small repacked soil columns in a closed system (SCR), (2) long repacked soil columns in a closed system (LCR), (3) small repacked or intact soil columns in an open system (SOI or SOR), (4) large flat soil columns containing macropores in a closed system (2DCR), and (5) large intact monoliths in a closed system (LCI). The five methods are described below.

Fig.2 Scheme of selected laboratory methods for measuring gas diffusion coefficient. 
Table 1 Summary of existing simple gas diffusivity relationships

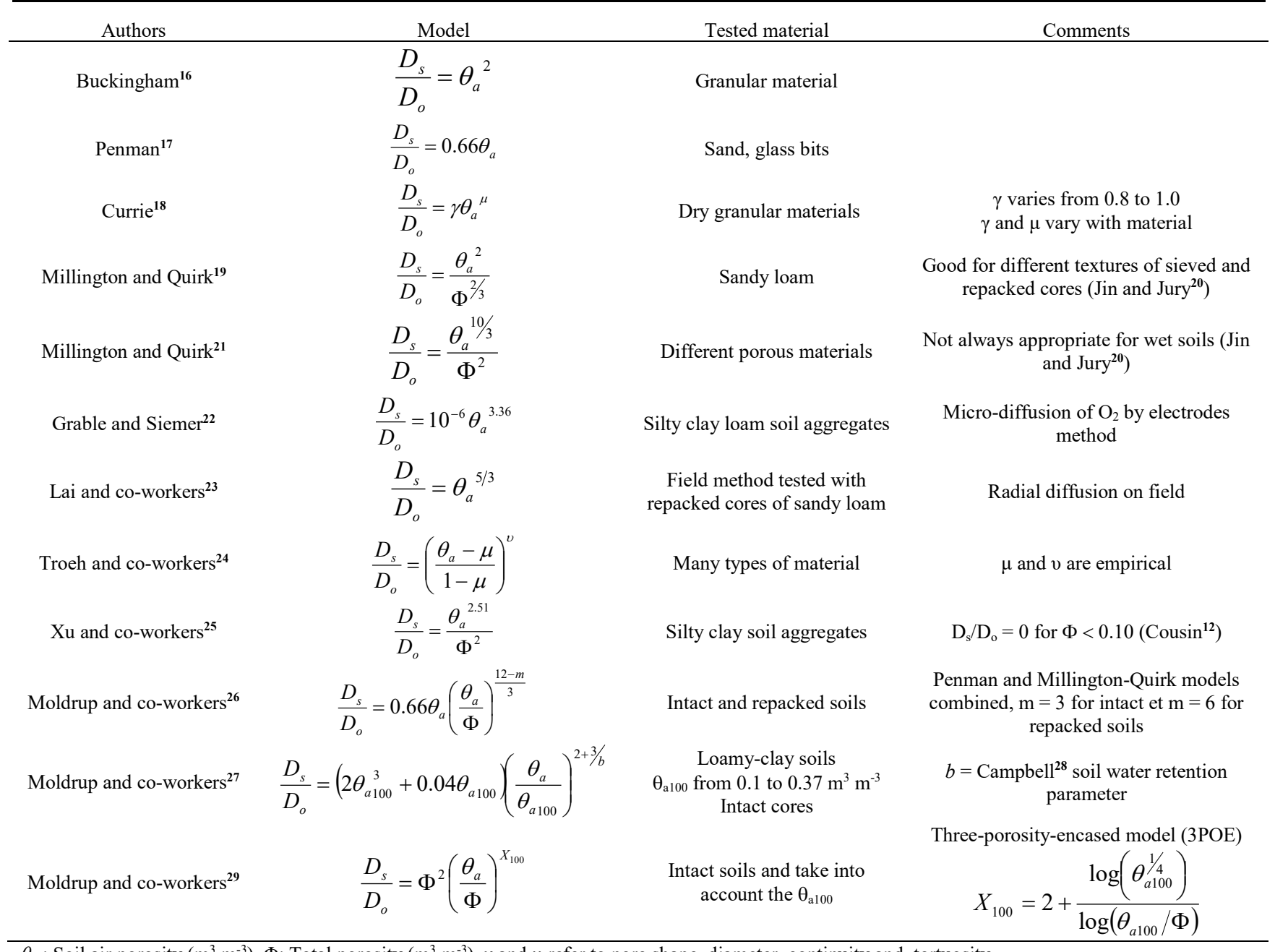

$\theta_{a}$ : Soil air porosity $\left(\mathrm{m}^{3} \mathrm{~m}^{-3}\right), \Phi$ : Total porosity $\left(\mathrm{m}^{3} \mathrm{~m}^{-3}\right), \gamma$ and $\mu$ refer to pore shape, diameter, continuity and tortuosity. 
Table 2 Description of selected field methods for measuring $D_{s}$

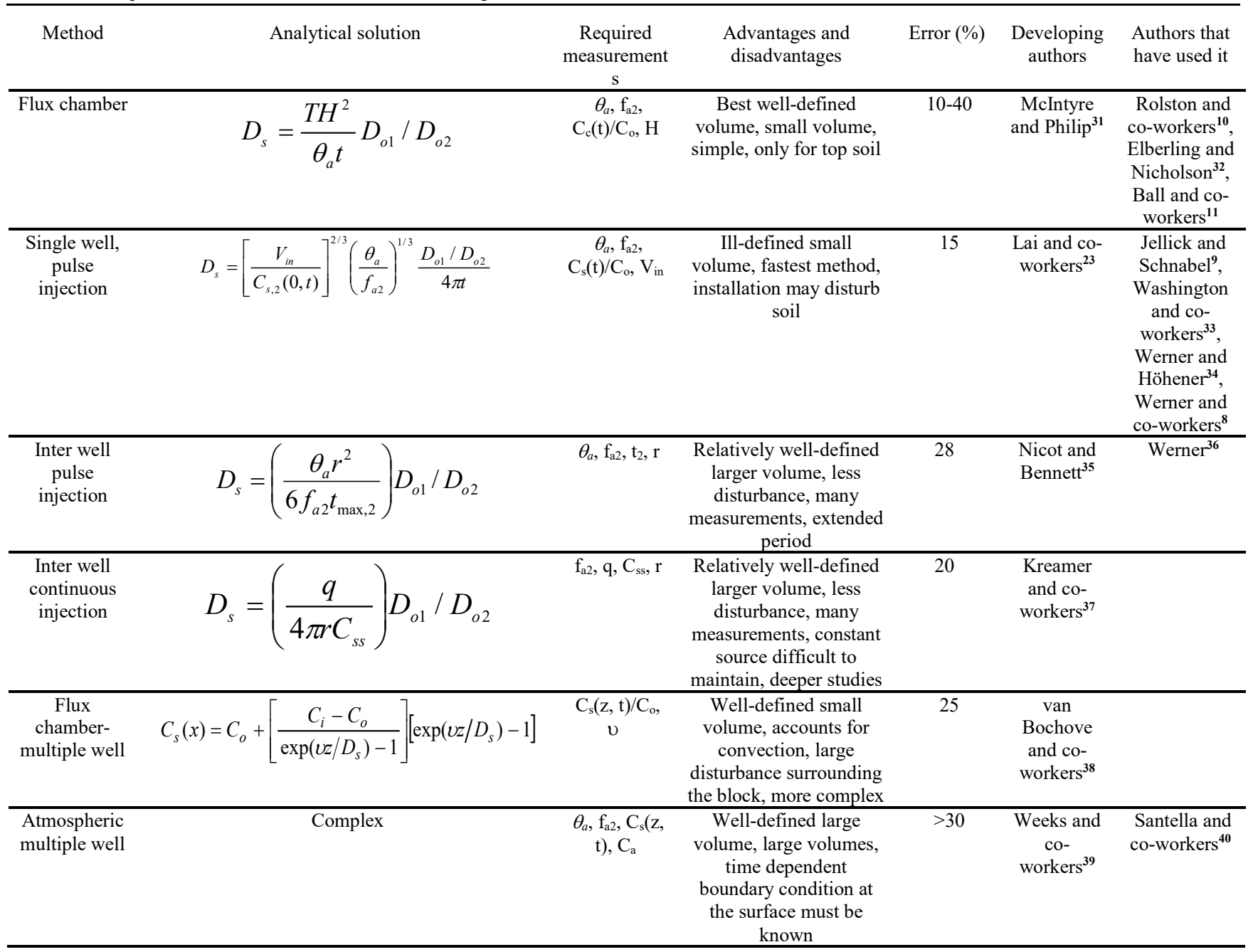

Completed and adapted from Werner and co-workers ${ }^{8}$

$\theta_{a}$ : air-filled porosity $\left(\mathrm{m}^{3} \mathrm{~m}^{-3}\right), \mathrm{f}_{\mathrm{a}}$ : fraction of the total mass of the compound in the soil air, $\mathrm{D}_{\mathrm{s}}$ : gas diffusion coefficient in the soil $\left(\mathrm{m}^{2} \mathrm{~s}^{-1}\right), \mathrm{D}_{\mathrm{o}}$ : gas diffusion coefficient in the air $\left(\mathrm{m}^{2} \mathrm{~s}^{-1}\right), \mathrm{C}_{\mathrm{o}}$ : applied gas concentration $\left(\mathrm{g} \mathrm{m}^{-3}\right), \mathrm{C}_{\mathrm{s}}$ : soil gas concentration $\left(\mathrm{g} \mathrm{m}^{-3}\right), \mathrm{C}_{\mathrm{ss}}$ : steady state gas concentration $\left(\mathrm{g} \mathrm{m}^{-3}\right)$, $\mathrm{C}_{\mathrm{c}}$ : chamber gas concentration $\left(\mathrm{g} \mathrm{m}^{-3}\right), \mathrm{H}$ : chamber height $(\mathrm{m}), \mathrm{V}_{\mathrm{in}}$ : volume of gas injected $\left(\mathrm{m}^{3}\right)$, q: rate of gas diffusion from source $\left(\mathrm{g} \mathrm{s}^{-1}\right), \mathrm{r}$ : distance from the point source $(\mathrm{m}), \mathrm{v}$ : gas apparent velocity $\left(\mathrm{m} \mathrm{s}^{-1}\right)$, $\mathrm{t}_{\max }$ : time $(\mathrm{s})$ for maximum tracer concentration at some distance $\mathrm{r}(\mathrm{m})$ from the injection point, indices 1 and 2 refer to the compound of interest and the tracer gas. 
Table 3 Description of selected laboratory methods for measuring $D_{s}$

\begin{tabular}{|c|c|c|c|c|c|}
\hline Method & Solution & $\begin{array}{l}\text { Boundary } \\
\text { conditions }\end{array}$ & $\begin{array}{c}\text { Required } \\
\text { measurements }\end{array}$ & Advantages & Disadvantages \\
\hline SCR & $\begin{array}{l}\ln \left(\frac{C_{i}(L, t)}{C_{i}(L, \infty)}\right)=-D_{s} A t / V_{i} L \\
\quad \text { for long duration }\left(\text { Taylor }^{41}\right)\end{array}$ & $\begin{array}{l}\mathrm{C}(0,0)=\mathrm{C}_{\mathrm{o}} \\
\mathrm{C}(\mathrm{L}, 0)=0 \\
\mathrm{C}(0, \mathrm{t})=\mathrm{C}_{\mathrm{i}}(\mathrm{t}) \\
\mathrm{C}(\mathrm{L}, \mathrm{t})=\mathrm{C}_{\mathrm{D}}(\mathrm{t})\end{array}$ & $\mathrm{C}_{\mathrm{i}}(\mathrm{t}), \mathrm{L}, \mathrm{V}_{\mathrm{i}}$ & $\begin{array}{l}\text { For small intact or } \\
\text { repacked samples, } \\
\text { fast, only few } \\
\text { measurements } \\
\text { required, any gas } \\
\text { can be used included } \\
\text { air gases } \\
\end{array}$ & $\begin{array}{c}\text { Can not detect } \\
\text { heterogeneity unless } \\
\text { large number of samples } \\
\text { that include } \\
\text { heterogeneity }\end{array}$ \\
\hline & $\left(t_{3}-t_{1}\right) \quad S \quad \overline{\left(C_{s}\left(z_{3}, t_{2}\right)-C\left(z_{1}, t_{2}\right)\right)}$ & $\begin{array}{c}\mathrm{C}(0,0)=\mathrm{C}_{\mathrm{o}} \\
\mathrm{C}(\mathrm{L}, 0)=0 \\
\mathrm{C}(0, \mathrm{t})=\mathrm{C}_{\mathrm{o}} \\
\mathrm{C}(\mathrm{L}, \mathrm{t})=\mathrm{C}_{\mathrm{D}}(\mathrm{t})\end{array}$ & $\mathrm{C}_{\mathrm{s}}(\mathrm{z}, \mathrm{t}), \mathrm{V}_{\mathrm{s}}, \mathrm{S}$ & $\begin{array}{c}\text { For repacked } \\
\text { samples, allows the } \\
\text { study of layered } \\
\text { media or gradient in } \\
\theta_{a}\end{array}$ & $\begin{array}{l}\text { More sensitive to wall } \\
\text { effect, difficult to pack, } \\
\text { different mathematical } \\
\text { approaches for solving }\end{array}$ \\
\hline $\begin{array}{l}\text { SOR or } \\
\text { SOI }\end{array}$ & $\begin{array}{l}\frac{C_{i}(t)}{C_{i}(0)}=\frac{2 h \exp \left(-D_{s} \alpha_{1}^{2} t / \theta_{a}\right)}{L\left(\alpha_{1}^{2}+h^{2}\right)+h} \\
\quad\left(\text { Carslaw and Jeager }{ }^{42}\right)\end{array}$ & $\begin{array}{c}\mathrm{C}(0,0)=\mathrm{C}_{\mathrm{o}} \\
\mathrm{C}(\mathrm{L}, 0)=0 \\
\mathrm{C}(0, \mathrm{t})=\mathrm{C}_{\mathrm{i}}(\mathrm{t}) \\
\mathrm{C}(\mathrm{L}, \mathrm{t})=0\end{array}$ & $\overline{C_{i}(t), L, V_{i}}$ & $\begin{array}{l}\text { For small intact or } \\
\text { repacked samples, } \\
\text { the simplest, only } \\
\text { few measurements } \\
\text { required } \\
\end{array}$ & $\begin{array}{l}\text { Restricted to gas not in } \\
\text { ambient air, sensitive to } \\
\text { atmospheric pressure } \\
\text { change, drying of wet } \\
\text { core } \\
\end{array}$ \\
\hline LCR & $\begin{array}{c}D_{s}=-\frac{\left(C_{s}\left(x_{1}, z_{2}, t_{3}\right)-C_{s}\left(x_{1}, z_{2}, t_{1}\right)\right)}{\left(t_{3}-t_{1}\right)} \frac{V_{s}}{S} \frac{\left(z_{3}-z_{1}\right)}{\left(C_{s}\left(x_{1}, z_{3}, t_{2}\right)-C_{s}\left(x_{1}, z_{1}, t_{2}\right)\right)} \\
\quad \text { (assuming vertical flux) }\end{array}$ & $\begin{array}{c}C(0,0)=C_{0} \\
C(L, 0)=0 \\
C(0, t)=C_{0} \\
C(L, t)=C_{D}(t)\end{array}$ & $\begin{array}{l}C_{s}(x, z, t), V_{s}, S \\
C_{D}(t), C_{i}(t), V_{i} \\
V_{D}\end{array}$ & $\begin{array}{l}\text { For heterogeneities } \\
\text { at larger scale } \\
\text { (REV) and in 3D at } \\
\text { small scale, less soil } \\
\text { samples }\end{array}$ & $\begin{array}{c}\text { Heavy, difficult to } \\
\text { homogeneously apply } \\
\text { gas, numerous gas } \\
\text { samples, calculation } \\
\text { error related to sampling } \\
\text { time, length of sampling } \\
\text { time, no control of soil } \\
\text { parameters and their } \\
\text { distribution in the soil } \\
\text { profile }\end{array}$ \\
\hline
\end{tabular}

$\mathrm{V}_{\mathrm{D}}$ : volume of the diffusion chamber $\left(\mathrm{m}^{3}\right), \mathrm{V}_{\mathrm{i}}$ : volume of the injection chamber, $\mathrm{V}_{\mathrm{s}}$ : soil volume covered by the sampling ports, $\mathrm{S}$ : surface of the soil column $\left(\mathrm{m}^{2}\right)$, L: length of the soil column $(\mathrm{m}), \mathrm{C}_{\mathrm{i}}(\mathrm{t})$ : gas concentration in the injection chamber at a time $\mathrm{t}\left(\mathrm{g} \mathrm{m}^{-3}\right)$, $\mathrm{C}_{\mathrm{D}}(\mathrm{t})$ : gas concentration in the diffusion chamber at a time $\mathrm{t}\left(\mathrm{g} \mathrm{m}^{-3}\right), \mathrm{C}_{\mathrm{s}}(\mathrm{x}, \mathrm{z}, \mathrm{t})$ : gas concentration $\left(\mathrm{g} \mathrm{m}^{-3}\right)$ in the soil profile at a certain distance $\mathrm{z}$ from the injection point at a distance $\mathrm{x}$ from the left boundary at a time $t$.

A loamy sand with $77 \%$ sand, $17 \%$ silt, and $6 \%$ clay in the Ap horizon (near the soil surface) and $90 \%$ sand, $7 \%$ silt, and $3 \%$ clay in the $\mathrm{B}_{\mathrm{f}}$ horizon (below) was selected for all methods. The Ap horizon reached $0.2 \mathrm{~m}$ deep while the $\mathrm{B}_{\mathrm{f}}$ reached $0.5 \mathrm{~m}$ deep. The number of concretions and the bulk density significantly increased with depth $(1.25$ to $1.5 \mathrm{Mg}$ $\mathrm{m}^{-3}$ ). For all methods using repacked columns, composite samples were taken from the $B_{f}$ horizon only. For all methods using intact columns, the samples were taken a few meters apart using the core method ${ }^{\mathbf{4 3}}$ for small samples and the cylindrical method ${ }^{44}$ for the large monoliths. For the repacked cores, the soil was sieved through a $2-\mathrm{mm}$ mesh, dried at $105^{\circ} \mathrm{C}$ for 24 hours and was hand-packed in fine layers to $1.3-1.4 \mathrm{Mg} \mathrm{m}^{-3}$. In the case of soil detachment from the casing, bentonite was used to fill up the gap between the soil and the casing. The systems were opened at the end of each test to measure the exact $\theta_{v},{ }^{45} \rho_{a},{ }^{43} \theta_{a},{ }^{46}$ and to observe if cracking, detachment, soil movement, or other anomalies occurred.

The gas injection was similar for all methods with either pulse or continuous injection. The temperature $\left(20^{\circ} \mathrm{C} \pm 2^{\circ} \mathrm{C}\right)$ and atmospheric pressure were maintained constant during the experiment. The systems were gas tight, except for the upper part of the SOI and SOR methods. Prior to injecting the tracer gas, the systems were flushed with humid air. Either argon or neon was injected. The values of $D_{o}$ at atmospheric pressure and at $20^{\circ} \mathrm{C}$ for $\mathrm{Ar}$ and $\mathrm{Ne}$ are $2.0 \mathrm{x}$ $10^{-5}$ and $6.5 \times 10^{-5} \mathrm{~m}^{2} \mathrm{~s}^{-1}$, respectively. ${ }^{47,48}$

The gas sampling technique was the same for all methods. When sampling from soils, $100 \mu \mathrm{l}$ gas tight syringes (Hamilton Company, Reno, Nevada, USA, no. 81030) were used, whereas for chambers $250 \mu \mathrm{l}$ gas tight syringes (Hamilton Company, Reno, Nevada, USA, no. 81130) were employed. Gas samples were immediatly inserted into 0.011 L gas tight vials (model 5182-0838, Agilent, Wilmington, DE, USA) with rubber butyl septa (Butyl, lyophilisation, 73828A-21, Kimble Glass Inc., Vireland, NI, USA). Ar or Ne concentrations were measured as soon as possible with a gas chromatograph $(6890 \mathrm{~N}$, Agilent, Wilmington, DE, USA) equipped with a Headspace autosampler (7694, Agilent), a HP-Molsiv column (19095P-MSO, 30m, Agilent, Wilmington), a TCD detector, and Helium (UHP 5.0, Praxair, Darbury, CT, USA) as the carrier gas. The limit of detection was $0.74(\mathrm{CV}=6.4 \%) \mathrm{mg} \mathrm{L}^{-1}$ for $\mathrm{Ar}$ and $0.17(\mathrm{CV}=5.1 \%) \mathrm{mg} \mathrm{L}^{-1}$ for $\mathrm{Ne}$. 


\section{Small repacked column in a closed system (SCR)}

This method is also referred to as the two-chamber method. ${ }^{49}$ The soil was re-moistened until the desired water content was attained, and hand-packed in a $0.10 \mathrm{~m}$-long ABS tube $4 \mathrm{~mm}$ thick with a inner diameter of $0.05 \mathrm{~m}$ (surface area of $2.1 \times 10^{-3} \mathrm{~m}^{2}$ ). Three replicates were prepared for each of the three $\theta_{a}\left(0.3,0.4\right.$, and $\left.0.5 \mathrm{~m}^{3} \mathrm{~m}^{-3}\right)$. A set-up similar to Reible and Shair ${ }^{\mathbf{5 0}}$ was built (Fig. 2). The column was positioned horizontally in order to limit the creation of a hydraulic gradient, thus moisture redistribution within the column. Ne samples $(100 \mu$ l $)$ were simultaneously collected from both chambers on several occasions within the first $6 \mathrm{hrs}$. The $D_{s}$ was calculated using the equation given in Table $3 .{ }^{\mathbf{4 1 , 5 0}}$

\section{Long repacked column in a closed system (LCR)}

The same ABS tube, injection and flux chambers were used as for the SCR method, but the soil columns were $0.475 \mathrm{~m}$ long (Fig. 2; Table 3). One sample was prepared for the same values of $\theta_{a}$ mentioned above. Sampling frequency was previously determined to obtain about 15 sampling events per test. Ar samples were withdrawn simultaneously from both chambers. In addition, gas samples were taken at a $0.05 \mathrm{~m}$ interval ( 8 sampling ports) along the soil columns (Fig. 2). The systems were also horizontally installed and rotated occasionally before measurement to limit the impact of water redistribution. The gas diffusion coefficient was calculated using the finite difference method. ${ }^{\mathbf{5 1}}$

\section{Small intact or repacked columns in an open system (SOI or SOR)}

This method is also known as the Currie Method. ${ }^{49}$ The 0.077-m long column casing was made of PVC tube with an inner diameter of $0.1 \mathrm{~m}$ (surface area of $7.9 \times 10^{-3} \mathrm{~m}^{2}$ ). Soil $\theta_{a}$ was controlled by imposing suction with tension tables or pressure plates after $24 \mathrm{hrs}$ of saturation. ${ }^{\mathbf{5 2}}$ Therefore, contrary to the other methods presented above, each sample was tested under several $\theta_{a}$, starting with the wettest condition. Any change in soil volume was measured and corrections to $\theta_{a}$ were made accordingly. The injection chamber, made of acrylic, had a volume of $7.78 \times 10^{-3} \mathrm{~m}^{3}$. Ar was allowed to diffuse from the chamber through the soil for more than $200 \mathrm{~min}$. Air above the soil core was renewed with low air flow. $D_{s}$ was calculated using the solution of Carslaw and Jaeger ${ }^{\mathbf{4 2}}$ as presented in Rolston ${ }^{\mathbf{5 3}}$ (Table 3).

\section{Large 2D repacked column with macropores in a closed system (2DCR)}

This method (Fig. 2, Table 3) is similar to the methods used in other studies. ${ }^{\mathbf{5 4 5 5}}$ The soil columns had the following inner dimensions: $0.6 \mathrm{~m}$ wide, $0.025 \mathrm{~m}$ thick and $0.6 \mathrm{~m}$ high. They were made of $0.012 \mathrm{~m}$ thick acrylic. Linear macropores open to the soil surface with a diameter of 0.005 $\mathrm{m}$ and a length of $0.3 \mathrm{~m}$ were created during packing as in Allaire-Leung and co-workers ${ }^{\mathbf{5 6}}$ using coarse nylon mesh fabric held on an aluminium screen After packing, a $0.05 \mathrm{~m}$ head of water was applied at the soil surface for $5 \mathrm{~min}$ and the soil surface was covered to minimize evaporation. Five days were allowed for equilibrium. Eighty one sampling ports were regularly distributed within the soil sample (Fig. 2 ). Ne concentrations were measured five times during 24 hrs. The experiment was repeated three times with various macroporosities.

\section{Large monoliths in a closed system (LCI)}

Three monoliths were extracted using the method described by Allaire and van Bochove. ${ }^{44}$ The $0.45 \mathrm{~m}$ inner diameter and $0.40 \mathrm{~m}$ high casing was made of $0.05 \mathrm{~m}$ thick ABS. The samples were constituted of the two horizons, the $A_{p}$ horizon at the soil surface and the $\mathrm{B}_{\mathrm{f}}$ below. The initial $\theta_{a}$ of the monoliths was not controlled. Ne concentration was maintained constant inside the injection chamber. During diffusion, its concentration was measured at a distance of $0.05 \mathrm{~m}$ in the vertical direction, and five equally spaced radial positions (Fig. 2). Sampling was completed seven times during $48 \mathrm{hrs}$. $D_{s} / D_{o}$ was calculated by finite differences (Table 3). $D_{s} / D_{o}$ values given in Fig. 3 correspond to each horizon of each monolith. Lateral flow was not considered in the calculations.

The graphing software for gas distribution in the soil profile was Surfer v.8 (Golden Software, Co, USA) using inverse method for interpolation.

\section{Results and discussion}

\section{Comparison between methods}

Using the SOI as the baseline for comparison (larger number of tests covering a wide range of $\theta_{a}$ ), it can be observed in Fig. 3 that the SOR method gave similar values of $D_{s} / D_{o}$, over the entire range of $\theta_{a}$ for which the experiment was performed. Nonetheless, the tendency is that repacked cores yield slightly higher values of $D_{s} / D_{o}$ than intact cores $(14 \%$ is the greatest difference). This is due to fine cracks that developed during the drying process of the repacked cores. These cracks were comparable and sometime larger than the cracks in the intact cores. In addition, some intact cores had concretions resulting in $D_{s} / D_{o}$ lower than in the repacked cores. Values of $D_{s} / D_{o}$ obtained with the SCR method followed the same tendency obtained with the baseline method. However, the values with the SCR method were obtained for $\theta_{a}>0.27 \mathrm{~m}^{3} \mathrm{~m}^{-3}$.

The LCI method can also predict $D_{s} / D_{o}$ values similar to those by the baseline method, although the comparison only stands for $\theta_{a}$ up to $0.25 \mathrm{~m}^{3} \mathrm{~m}^{-3}$. For $\theta_{a}>0.25 \mathrm{~m}^{3} \mathrm{~m}^{-3}$, high values of $D_{s} / D_{o}$ are predicted with the LCR method. This was probably due to soil loosening. At the end of the experiment, some soil was observed in the flux chamber, indicating that it passed through the screen. This probably occurred because the soil was very dry (about $3 \%$ moisture), and the column was horizontally installed and rotated to avoid water redistribution in the column (too much handling). Preferential paths may have developed along the 
casing but it is difficult to evaluate the data for evidence of that.

Fig.3 $D_{s} / D_{o}$ obtained for different air-filled porosity and using different measuring methods.

The 2DCR method resulted in $D_{s} / D_{o}$ similar to the other methods when $D_{s} / D_{o}$ was calculated at points sufficiently distant $(>0.12 \mathrm{~m})$ from macropores, and this is valid for wet and dry conditions (presented together in Fig. 3). The $D_{s} / D_{o}$ values from the LCI method were similar with those from the 2DCR method. The values from LCI methods were calculated using the average gas concentration at each height. One value appears high with a $D_{s} / D_{o}$ of 0.14 . It corresponds to the horizon containing a large earthworm macropore ( $>4 \mathrm{~mm}$ diameter). No such macropore was observed in the other two monoliths used in the LCI method but fine cracks, such as those found in small cores, were observed. Otherwise, differences in $D_{s} / D_{o}$ between methods were negligible.

Overall, most of the $D_{s} / D_{o}$ values presented in Fig. 3 are comparable with other studies for intact ${ }^{25,29,30}$ and repacked $^{\mathbf{5 7}, \mathbf{5 8}}$ soil cores.

Finally, with the exception of the values obtained when macropores were present, all methods predicted similar values of $D_{s} / D_{o}$ at $\theta_{a}$ lower than approximately $0.4 \mathrm{~m}^{3} \mathrm{~m}^{-3}$ (Fig. 3). For higher $\theta_{a}$ values, the predicted values are scattered, which can be partly explained by soil loosening (LCR method) or by the presence of macropores. Therefore, any of these laboratory methods can be used for evaluating $D_{s} / D_{o}$ in soils. The choice of a method would depend upon several factors including simplicity, cost, and soil characteristics (presence of macropores).

\section{Spatial variability}

Heterogeneity causing preferential flow (PF) in soil is a key factor for gas flow. Several factors cause PF in soil, such as macropores (cracks and burrows), and heterogeneity in water distribution and pore size. The latter can be caused by vegetation (roots), wet-dry cycles, freeze-thaw cycles, and soil layering. Theoretically, intact cores should better represent gas movement in porous materials than repacked ones, because natural heterogeneity associated with PF is better represented in intact samples. ${ }^{59}$

Fig.4 Air-filled porosity and gas concentration distributions in a 2Dcolumn after $2 \mathrm{hrs}$, obtained with the second column (one open-surface macropore) and with a column without macropores of the 2DCR method.

However, methods using small samples, such as SCR, SOI and SOR yield similar values, as discussed previously. This results from the fact that intact and repacked small samples had similar physical properties at comparable $\theta_{a}$ and $\Phi$, and because of the naturally high variability of $D_{s} / D_{o}$. In addition, the small repacked and intact cores contained a similar number of fine cracks and no large features since large cracks, earthworm burrows, or similar features were avoided for the small intact samples, as is usually done in most studies.

The impact of features like macropores was evident with larger columns such as those used in 2DCR and LCI methods. Indeed, $D_{s} / D_{o}$ values calculated using the average concentration in a region around a macropore with the 2DCR was up to 6 times higher $(0.07$ vs. 0.01$)$ than values obtained away from macropores, for similar $\theta_{a}$ (Fig. 3).

Figure 4 presents the distribution of $\theta_{a}$ in $2 \mathrm{D}$ columns. $\theta_{a}$ was lower around the macropore and behind the wetting front. Normally, one would expect to obtain low gas concentrations in the wet zone (upper part of the column, where $\theta_{a}$ is lower) since gas movement is much slower in wet soil than in dry soil (Fig. 3). However, gas concentration did not follow the $\theta_{a}$ pattern. The distribution of gas concentration was similar to that expected in a much dryer soil with no macropores (Fig. 4). This can be explained by the gas movement through the macropore and diffusion in all directions, thus laterally giving the impression of a dryer soil.

The impact of soil heterogeneity, including macropore, on gas movement can also be observed in the Fig. 5. After 8 hrs of diffusion, $25 \%$ of the surface area at $0.25 \mathrm{~m}$ deep had a gas concentration one order of magnitude higher than another $15 \%$ of surface area. In addition, one would expect that near the soil surface, gas concentration would be lower since the gas was injected at the lower end of the column. However, $15 \%$ of the surface area at $0.25 \mathrm{~m}$ deep had a gas concentration higher than $10 \%$ of the surface at $0.45 \mathrm{~m}$ deep (Fig. 5). This phenomenon was observed in all monoliths. To explain this phenomenon, each column was carefully examined by cutting them into small layers, once gas flux measurements had been completed. The high variability in redox zones (Fig. 5: dark vs. light zones in the $\mathrm{B}_{\mathrm{f}}$ horizon at $0.35 \mathrm{~m}$ and deeper) is the long-term result of heterogeneity in soil properties. The variability in gas concentration was associated with large concretions, plowing layer, variability in $\theta_{v}$, cracks, earthworm burrows, and root channels; but the most important feature causing this high heterogeneity in gas movement was a large macropore in monolith 2 which resulted in this high $D_{s} / D_{o}$ value (Fig. 3). The gas moved upward from the injection chamber and then accumulated right below concretions where the soil has higher density and water content until it reached a PF path. It then moved upward in these PF paths and diffused in all directions in more permeable regions bypassing part of the soil monolith. The importance of PF of gas may become crucial in compacted soils, frozen soils with open macropores, wet soils, and for life forms that live deep in the soil because it allows oxygenation of soil section that would otherwise be anoxic. PF of gas also allows faster elimination of toxic gases in soil toward the atmosphere. It may help, for example, in interpreting the performance in $\mathrm{CH}_{4}$ oxidation by methanothrophic bacteria in landfill cover materials. This information is also important for interpreting field data, planning spatial measuring frequency, and sampling size. 
From this point, the choice of a laboratory method for measuring $D_{s} / D_{o}$ may, in part, depend on whether one is interested in variability in $D_{s} / D_{o}$ or in an overall average of $D_{s} / D_{o}$.

\section{Advantages and disadvantages of the methods}

As mentioned previously, similar $D_{s} / D_{o}$ can be obtained, irrespective of the method (Fig. 3), when samples are taken away from macrofeatures. It was shown that preferential paths are very important to study gas diffusion in soil. The difficulty of sampling methods to preserve these paths in the cores is a reason for in situ method to be attractive. However, in situ method also have there drawbacks. During installation of the equipement in the field, the disturbance of soil is usually high and may actually be higher than the disturbance in intact cores. In situ measurement is complex because of three dimensional flow. Lateral gas movement is thus often a problem for mass balance. In addition, boundary conditions are often difficult to control or measure which render the $D_{s} / D_{o}$ calculations less precise. For these reasons, laboratory method with undisturbed soil cores brought to the laboratory may be as representative to field method when values of small scale $D_{s} / D_{o}$ is of interest. But the choice of a method depends on cost, ease of use, and precision, to name a few. In the following, some advantages and pitfalls related to the use of each method are described.

Fig.5 Gas concentration distributions and associated photos in two large cylindrical monoliths after $8 \mathrm{hrs}$ in different depths obtained with the LCI method.

In the case of small samples, $\theta_{a}$ can easily be modified by installing the samples on pressure plates or tension tables. As the soil column becomes longer (LCR), a uniform $\theta_{a}$ becomes harder to obtain, particularly when the column is installed vertically. The problems caused by such a gradient may be overcome by withdrawing several gas samples along the column but $\theta_{a}$ must be measured along the column. However, this introduces more complexity to the tests. The 2DCR method offered the opportunity to cover a wide range of $\theta_{a}$. This could be achieved either through packing at different $\theta_{a}$ or by infiltrating water at the soil surface. In this study, the soil was initially dry and the water did not infiltrate the entire column. As a result, preferential paths were created using macropores. This technique presents the advantage that $D_{s} / D_{o}$ could be calculated in low and high $\theta_{a}$ regions during a single test. Comparatively, the large intact soil cores of the LCI method were too big for any tension tables rendering the control of $\theta_{a}$ difficult, which in this experiment, resulted in a narrow range of $\theta_{a}$ (Fig. 3).

Generally, from the point of view of boundary conditions, a variable (decreasing) concentration boundary condition at the injection level is easier than maintaining a constant concentration in the injection chamber or a zero concentration in the atmosphere or in the flux chamber.
Variable boundary conditions are also less costly because there is no need for instrumentation for controlling the flux. Also, the time required to reach a constant gas concentration in a large injection chamber may be long (Fig. 6) which increases the risk of gas leakage from the injection chamber to the soil column. In addition, a closed boundary condition offers the advantage of a larger choice of tracers. In an open system, the choice is restricted, because gases present in the air are usually not appropriate tracers.

Simplicity and cost are also key factors in choosing a method. The computation of $D_{s} / D_{o}$ using gas concentration monitoring obtained from the injection and/or flux chambers only, such as was done in this study in the SCR, SOR, or SOI methods, is relatively fast, easy, and requires only a few samples. For example, about 15 samples are necessary with the SOI or SOR methods to obtain $D_{s} / D_{o}$. However, no information can be obtained as far as gas movement within the soil; only the overall result is computed. The most costly and complex method remains the LCI (large monoliths) method. This is not only associated with the costs related to sampling the core, but also to the large number of gas samples that have to be taken during each test in order to fully profit from the advantages that come with this kind of test.

Error related to packing and sampling small cores may affect $D_{S} / D_{o}$ estimate by up to $5 \%$. Homogeneous packing is difficult especially as the core becomes larger. Higher length to diameter ratio (SCR vs. LCR) would render packing more difficult resulting in decreased homogeneity in $\theta_{a}$. Higher ratio also increases the importance of flows along the boundary (cell walls). Sampling intact cores usually slightly increases soil density $^{\mathbf{4 4}}$ mostly in less dense soils (e.g. upper horizon). In addition, higher length to diameter ratio usually reinforces the impact of sampling on density ${ }^{44}$.

Error is also associated to calculations. The precision with instantaneous profile calculations (Table 2) depends upon the time interval between sampling points of the same sampling event. The instantaneous profile method for $D_{s} / D_{o}$ calculation requires the gas concentration at four different points (see Equ. in Table 3). The precision with instantaneous profile calculations depends upon the time required to take two samples during a sampling event because the calculations assume instantaneous sampling. Calculations are based upon discrete times assuming instantaneous sampling. It took about $2 \mathrm{~min}$. for two persons for sampling all points in the LCR system, but the time lag between sampling may result in more than $5 \%$ error in early time (e.g. 20 min.) after diffusion starts in fast flow condition (e.g. when the soil is dry) and may be as low as $1 \%$ after longer time period.

Similar errors associated with the 2DCR and LCI methods arise from the number of samples required for mapping concentration distribution in the profile. For example, it took $25 \mathrm{~min}$. for two people to sample all points in the LCI and $15 \mathrm{~min}$. for two people to sample the entire 81 sampling points of the column of the 2DCR method. It took longer for the large monoliths because sampling was harder to perform, particularly when a stone, a root or other macro 
features blocked the needle penetration. If we take an early sampling event as an example (worst case), like $2 \mathrm{hrs}$ after the start of diffusion, and 25 min for sampling all ports with a systematic sampling and using the instantaneous profile calculation, error in estimated $D_{s} / D_{o}$ may reach up to $30 \%$. For random sampling (all 81 ports in any order), error in $D_{S} / D_{o}$ may reach up to $60 \%$. The error in $D_{s} / D_{o}$ significantly decreases as the time lag between two sampling events increases and as the time to sample all the ports during an event decreases. Therefore, the sampling sequence of all points should be planned according to the expected calculations (meaning the four points used for calculating $D_{s} / D_{o}$ ). When using an optimal sampling system, the error may be as low as $10 \%$.

Fig.6 Examples of gas concentration in injection and flux chambers during flux measurement of different methods.

Another source of error for all methods consists in the time required to reach a linear relationship between $\ln \left(\mathrm{C}_{\mathrm{c}} / \mathrm{Co}\right)$ vs. time (Fig. 6). The larger the injection chamber, the higher the error. The methods used for calculating $D_{s} / D_{o}$ based on gas concentration in the flux and/or in the injection chambers are also dependent upon precision on the dimensions of the chambers, but these errors together are usually less than $2 \%$.

The repacked columns suffer from the fatal flow of not reflecting preferential flow which can dominate the results and cause significant errors. The error in $D_{s} / D_{o}$ for macroporous soils may rise up to ten fold.

\section{Conclusion}

Gas diffusion measurement is important for many processes in soil. $D_{s} / D_{o}$ values measured with five laboratory methods were similar over a large range of air contents. The main differences in $D_{s} / D_{o}$ between the laboratory methods were mostly related to the presence of macropores and other soil heterogeneities that some methods can handle while others can not. The choice of the method must then depend on available apparatus, cost, precision and advantages of the methods related to the goal of the study.

\section{Acknowledgments}

The authors wish to thank the laboratory work of A.-C. Laliberté, C. Halde, M. Lafontaine, E. Cormier, and V. Juneau. The authors acknowledge the financial support of the Centre SÈVE of the Université Laval, National Science and Research Council of Canada (NSERC), and le Fonds Québécois de la Recherche sur la Nature et les Technologies (FQRNT).

\section{References}

1 USEPA, Solid Waste Management and Greenhouse Gases: A lifecycle assessment of emissions and sinks, United States Environmetal Protection Agency, 2nd edn., 2002, 136 p.

2 Environment Canada, Inventaire canadien des gaz à effet de serre 1990-2000, 2002, internet link : http://www.ec.gc.ca/pdb/ghg/1990 00 report/foreword f.cfm

3 C. Scheutz and P. Kjeldsen, J. Environ. Qual., 2004, 33, 72-79.

4 J. Chanton and K. Liptay, Global Biochem. Cycles, 2000, 14, 5160 .

5 M. Humer and P. Lechner, 7th International Waste Management and Landfill Symposium, Sta Margarita di Pula, Italy, 1999.

6 A. Adamsen and G. King, Appl. Environ. Microbiol., 1993, 59, 485-490.

7 J. Gliński and W. Stępniewski, Soil Aeration and Its Role for Plants, CRC Press, Boca Raton, Fla, U.S.A., 1985, 229 p.

8 D. Werner, P. Grathwohl and P. Höhener, Vadose Zone J., 2004, 3 1240-1248.

9 G.J. Jellick and R.R. Schnabel, Soil Sci. Soc. Am. J., 1986, 50, 18 23.

10 D.E. Rolston, R.D. Glauz and G.I. Grundmann, Soil Sci. Soc. Am. J., 1991, 55, 1536-1542.

11 B.C. Ball, C.A. Glasbey and E.A.G. Robertson, Eur. J. Soil Sci., 1994, 45, 3-13.

12 I. Cousin, Ph.D. Thesis, Université d'Orléans, 1996.

13 K. Shimamura, Soil Sci., 1992, 153, 274-279.

14 E.K. Yanful, J. Geotechn. Eng. ASCE, 1993, 119, 1207-1228.

15 A.H. Weerts, D. Kandhai, W. Bouten and P.M. Sloot, Soil Sci. Soc. Am. J., 2001, 65, 1577-1584.

16 E. Buckingham, Contributions to our knowledge of the aeration status of soils. USDA Bureau of Soils, Bulletin 25. Washington. DC, 1904.

17 H.L Penman, J. Agric. Sci., 1940, 30, 437-462.

18 J. A. Currie, British J. Appl. Phys., 1960, 11, 318-324.

19 R.J. Millington and J.P. Quirk, Transactions of the 7th International Congress of Soil Science, Madison, WI, U.S.A., 1960.

20 Y. Jin and W.A. Jury, Soil Sci. Soc. Am. J., 1996, 60, 66-71.

21 R.J. Millington and J.P. Quirk, Trans. Faraday Soc., 1961, 57, 1200-1207.

22 A.R. Grable and E.G. Siemer, Soil Sci. Soc. Am. Proc., 1968, 32, 180-186.

23 S.H. Lai, J.M. Tiedje and E. Erickson, Soil Sci. Soc. Am. J., 1976, 40, 3-6.

24 F.R. Troeh, J.D. Jabro and D. Kirkham, Goederma, 1982, 27, 239253.

25 X. Xu, J.L. Nieber and S.C. Gupta, Soil Sci. Soc. Am. J., 1992, 56, 1743-1750.

26 P. Moldrup, T. Olesen, D.E. Rolston and T. Yamaguchi, Soil Sci., 1997, 162, 632-640.

27 P. Moldrup, T. Olesen, P. Schjǿnning, T. Yamaguchi and D.E. Rolston, Soil Sci. Soc. Am. J., 2000b, 64, 94-100.

28 G.S. Campbell, Soil Sci., 1974, 117, 311-314.

29 P. Moldrup, T. Olesen, S. Yoshikawa, T. Komatsu and D.E. Rolston, Soil Sci., 2005b, 170, 854-866.

30 P. Moldrup, T. Olesen, S. Yoshikawa, T. Komatsu and D.E. Rolston, Soil Sci. Soc. Am. J., 2004, 68, 750-759.

31 D.S. McIntyre and J.R. Philip, Aust. J. Soil Res., 1964, 2, 133-145.

32 B. Elberling and R.V. Nicholson, Water Resour. Res., 1996, 32, 1773-1784.

33 J.W. Washington, A.W. Rose, E.J. Ciolkosz and R.R. Dobos, Soil Sci., 1994, 157, 65-76.

34 D. Werner and P. Höhener, Environ. Sci. Technol., 2003, 37, 25022510.

35 J.P. Nicot and P.C. Bennett, J. Environ. Eng. (Resten Va.), 1998, 124, 1038-1046.

36 D. Werner, Ph.D. Thesis, Swiss Federal Institute of Technology, 2002.

37 D.K. Kreamer, E.P. Weeks and G.M. Thompson, Water Resour. Res., 1988, 24, 331-341.

38 E. van Bochove, N. Bertrand and J. Caron. Soil Sci. Soc. Am. J., 1998, 62, 1178-1184.

39 E.P. Weeks, D.E. Earp and G.M. Thompson, Water Resour. Res., 1982, 18, 1365-1378.

40 N. Santella, D.T. Ho, P. Schlosser and M. Stute, Environ. Technol., 2003, 37, 1069-1074.

41 S.A. Taylor, Soil Sci. Soc. Am. Proc., 1949, 14, 55-61. 
42 H.S. Carslaw and J.C. Jaeger, Conduction of heat in solids, Claredon Press, Oxford, UK., 2nd edn., 1959.

43 G.R. Blake and K.H. Hartge, in Methods of soil analysis. Part 1. Physical and mineralogical method, ed. A. Klute, ASA-SSSA, Madison, WI, USA., Agron. No. 9, 2nd edn., 1986, ch. 13, pp. 363-376.

44 S.E. Allaire and E. van Bochove, Can. J. Soil Sci., 2007, 86, 885896.

45 W.H. Gardner, in Methods of soil analysis. Part 1. Physical and mineralogical method, ed. A. Klute, ASA-SSSA, Madison, WI, USA., Agron. No. 9, 2nd edn., 1986, ch. 21, pp. 493-544.

46 R.E. Danielson and P.L. Sutherland, in Methods of soil analysis. Part 1. Physical and mineralogical method, ed. A. Klute, ASASSSA, Madison, WI, USA., Agron. No. 9, 2nd edn., 1986, ch. 18, pp. 443-461.

47 J. Crank, The Mathematics of Diffusion, Oxford Science Publications, Oxford University Press, Great Britain, 2nd edn., $1975,414 \mathrm{p}$.

48 R.C. Roberts, in American Institute of Physics Handbook, ed. D. E. Gray, McGraw-Hill, New York, 3rd edn., 1972, ch. 2s, pp. 2-249$2-252$.
49 D.E. Rolston and P. Moldrup, in Methods of soil analysis. Part 4. Physical methods, ed. J.H. Dane and C. Topp, Book series no. 5, SSSA, Madison, WI, USA., 2002, ch. 4.3, pp. 1113-1140.

50 D.D. Reible and F.H. Shair, J. Soil Sci., 1982, 33, 165-174.

51 R. Naasz, J.C. Michel and S. Charpentier, Soil Sci. Soc. Am. J., 2005, 69, 13-22.

52 A. Klute, in Methods of soil analysis. Part 1. Physical and mineralogical method, ed. A. Klute, ASA-SSSA, Madison, WI, USA., Agron. No. 9, 2nd edn., 1986, ch. 26, pp.635-662.

53 D.E. Rolston, in Methods of soil analysis. Part 1. Physical and mineralogical method, ed. A. Klute, ASA-SSSA, Madison, WI, USA., Agron. No. 9, 2nd edn., 1986, ch. 46, pp. 1089-1102.

54 S.E. Allaire, S.R. Yates, F.F. Ernst and J. Gan, J. Environ. Qual., 2002, 31, 1079-1087.

55 S.E. Allaire, S.R. Yates and F.F. Ernst, Vadose Zone J., 2004, 3, 656-667.

56 S.E. Allaire-Leung, S.C. Gupta and J.F. Moncrief, J. Contam. Hydrol., 2000, 41, 283-301.

57 P. Moldrup, T. Olesen, J. Gamst, P. Schjǿnning and T. Yamaguchi, Soil Sci. Soc. Am. J., 2000a, 64, 1588-1594.

58 P. Moldrup, T. Olesen, S. Yoshikawa, T. Komatsu and D.E. Rolston, Soil Sci., 2005a, 170, 843-853.

59 J. Bouma, Agric. Water Manag., 1983, 6, 177-190. 
Flux Chamber Method

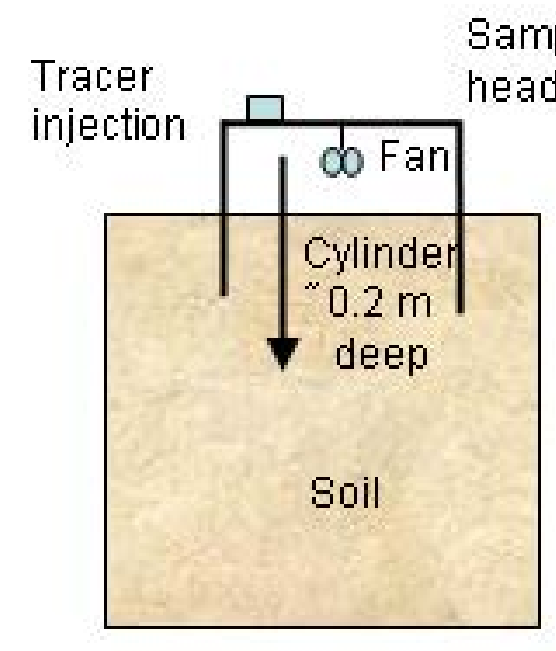

Interwell-Flux Chamber Method

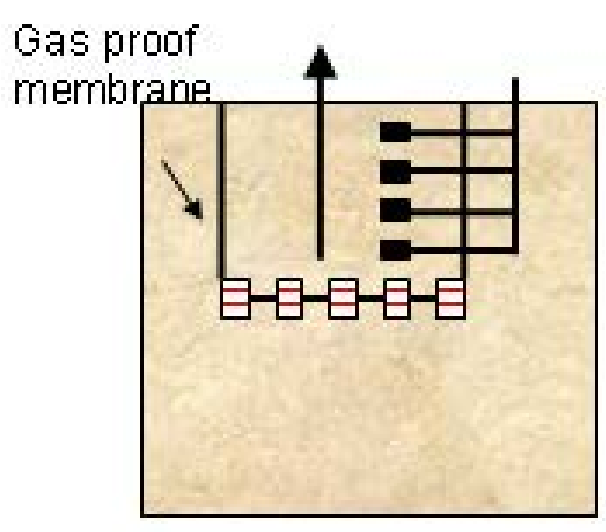

Single Well Method

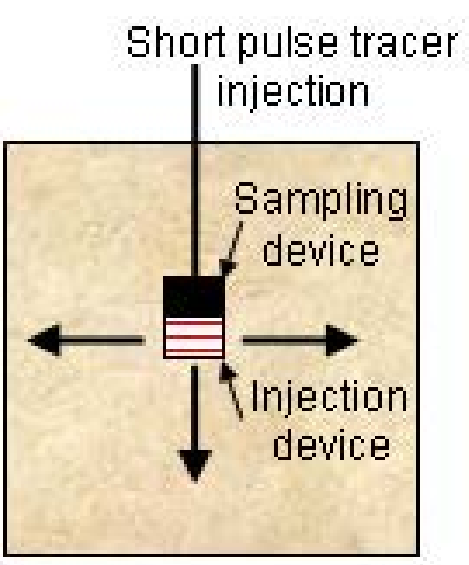

Atmospheric Tracer Method

Rare gas in the atmosphere

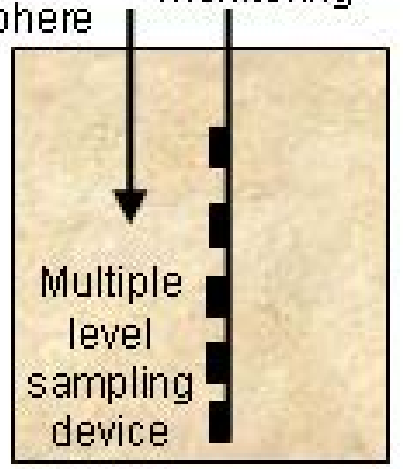

Interwell Method
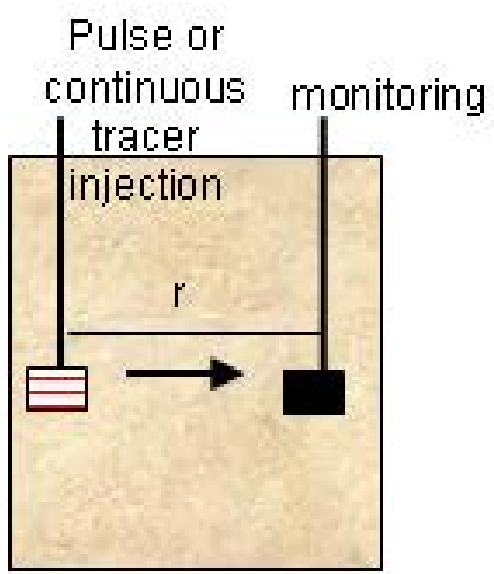

Figure 1. 
SGR

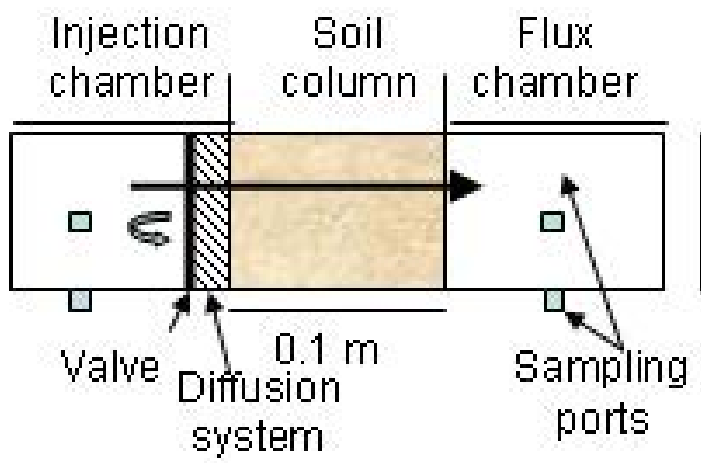

LGR

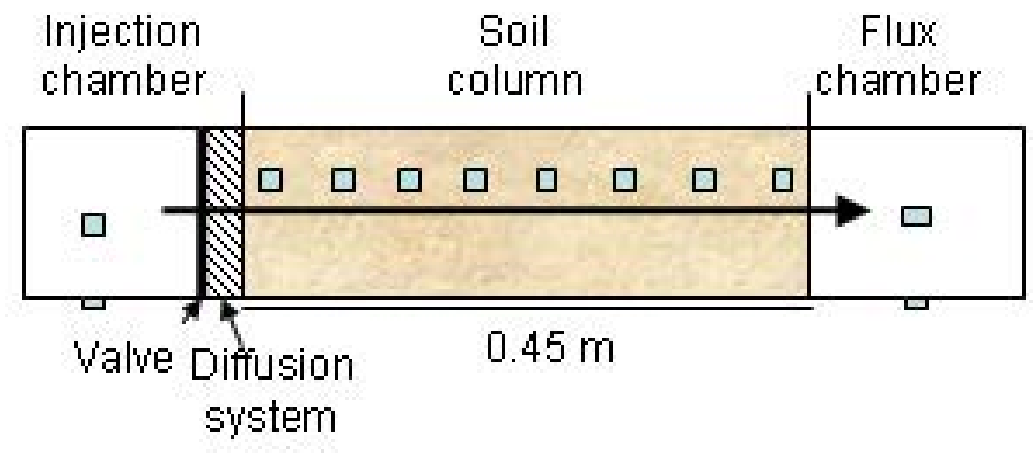

sol

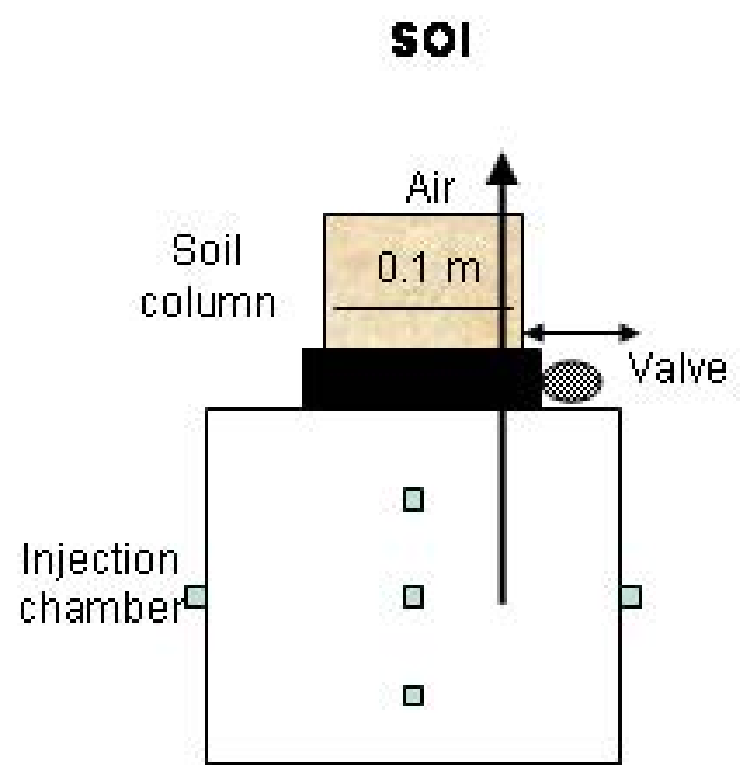

Figure 2.

\section{DGR}

\section{Flux chamber}

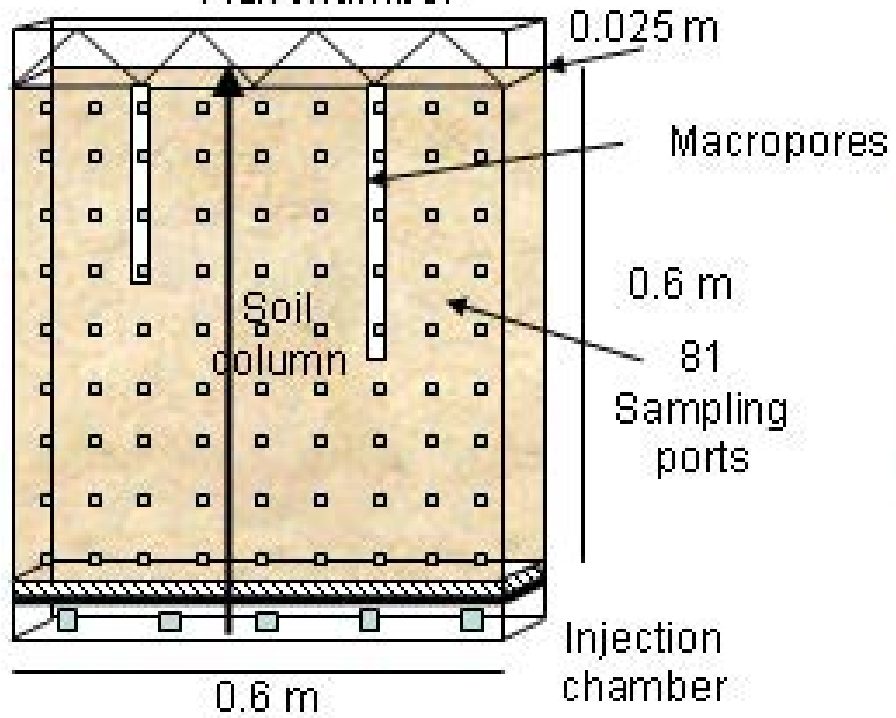

\section{LGI}

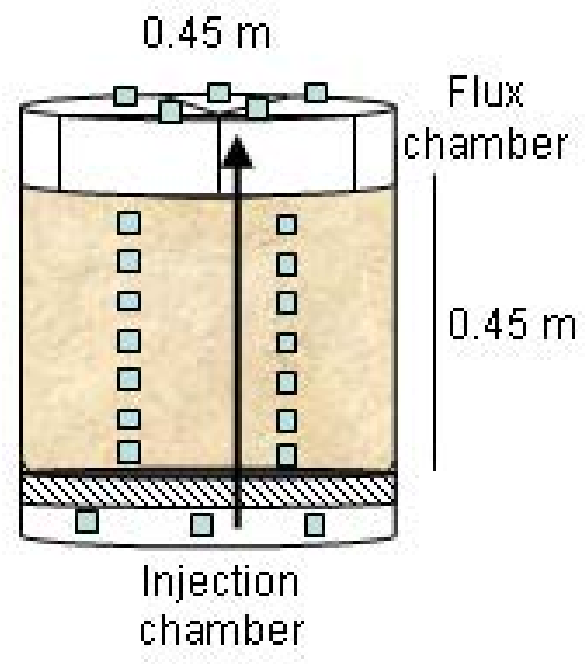




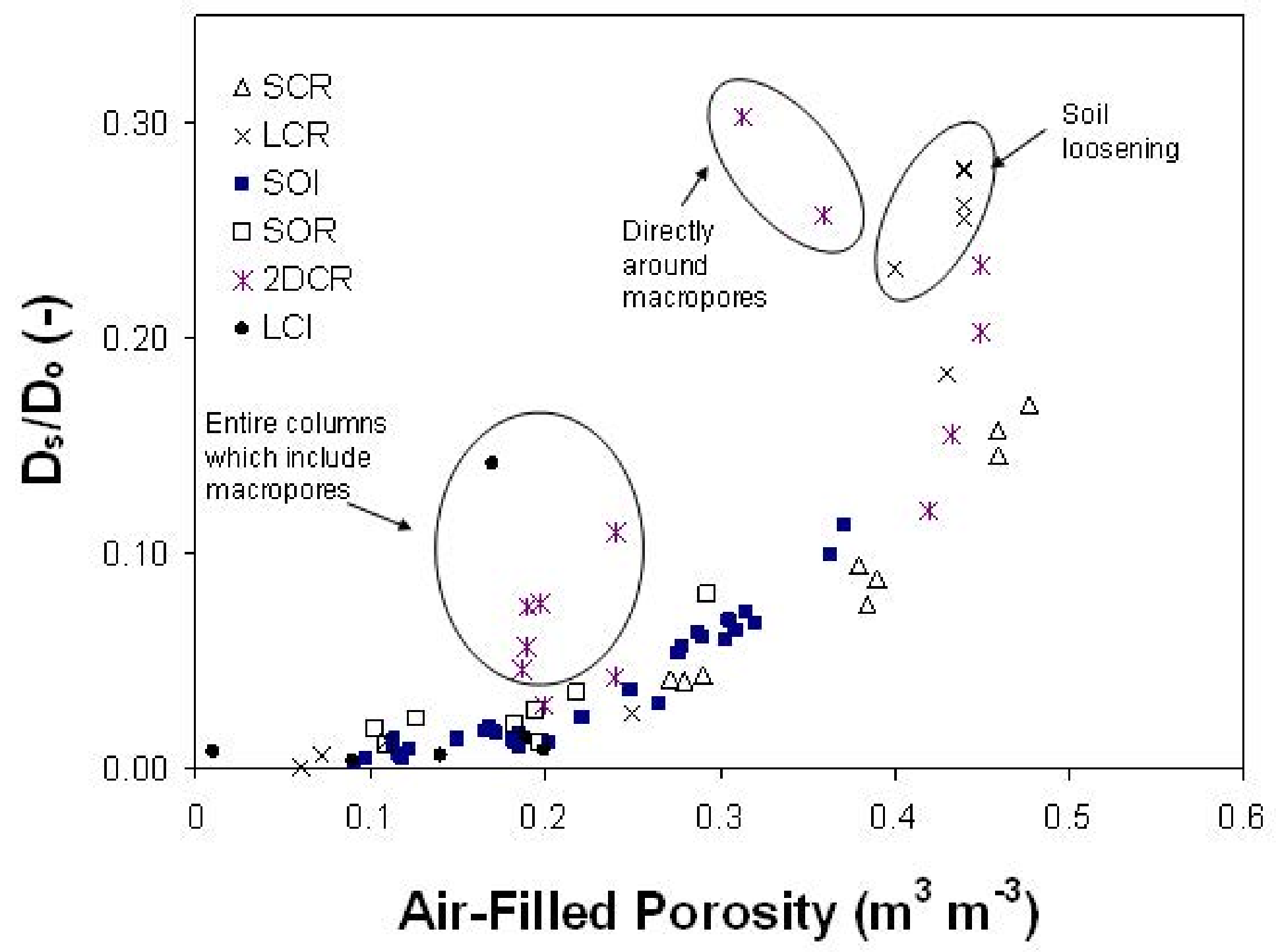

Figure 3 


\section{Air-Filled Porosity}

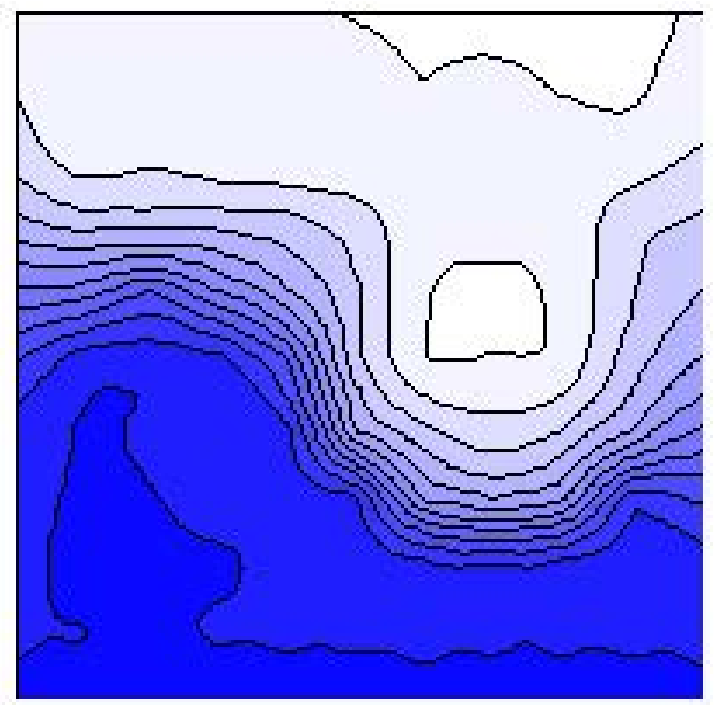

$$
\begin{gathered}
\text { O. }\left(\mathrm{m}^{2} \mathrm{~m}^{-3}\right) \\
0.5 \\
0.45 \\
\theta^{0.4} \\
-_{0.35}^{0.3} \\
\theta_{0.25}^{0.2} \\
\theta_{0.1}^{0.2}
\end{gathered}
$$

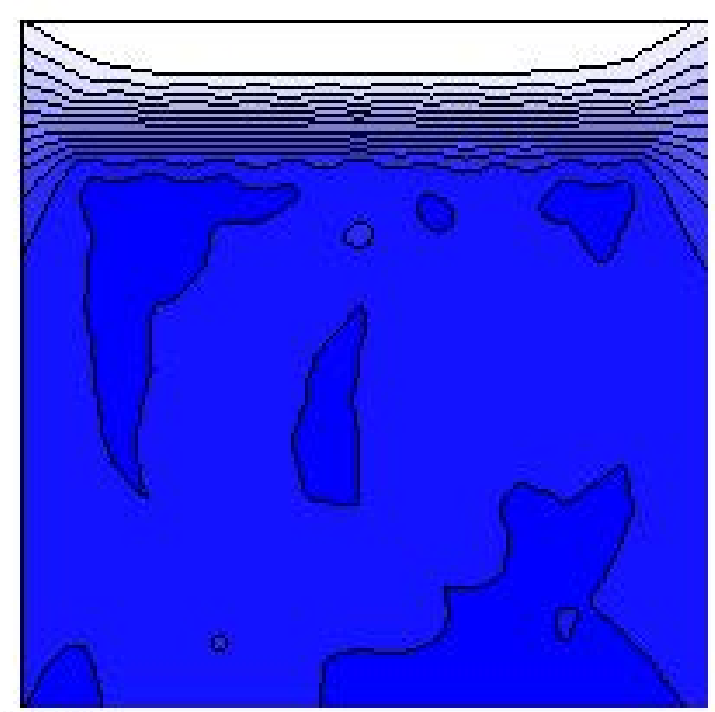

\section{Gas Goncentration}

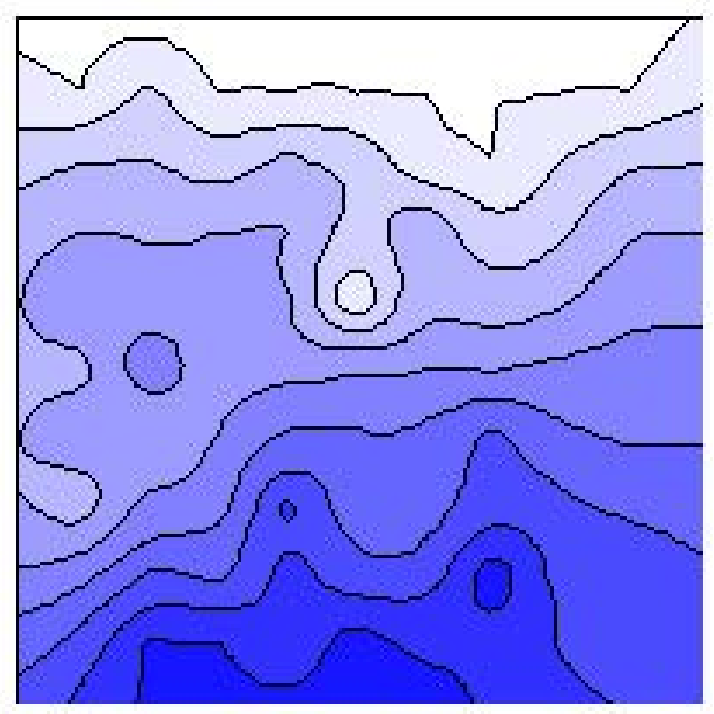

$$
\begin{aligned}
& C_{1}\left(\mathrm{mg} \mathrm{l}^{-1}\right) \\
& \text { D四 } \\
& \text { I } \\
& \text { 포 } \\
& \text { 즈 } \\
& \begin{array}{r}
15 \\
-15
\end{array} \\
& H^{15} \\
& \bigsqcup_{0}
\end{aligned}
$$

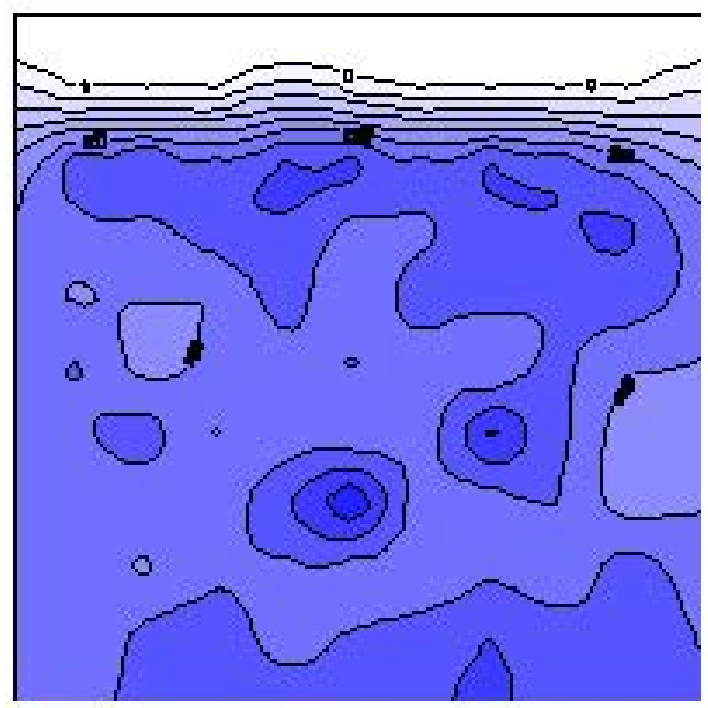




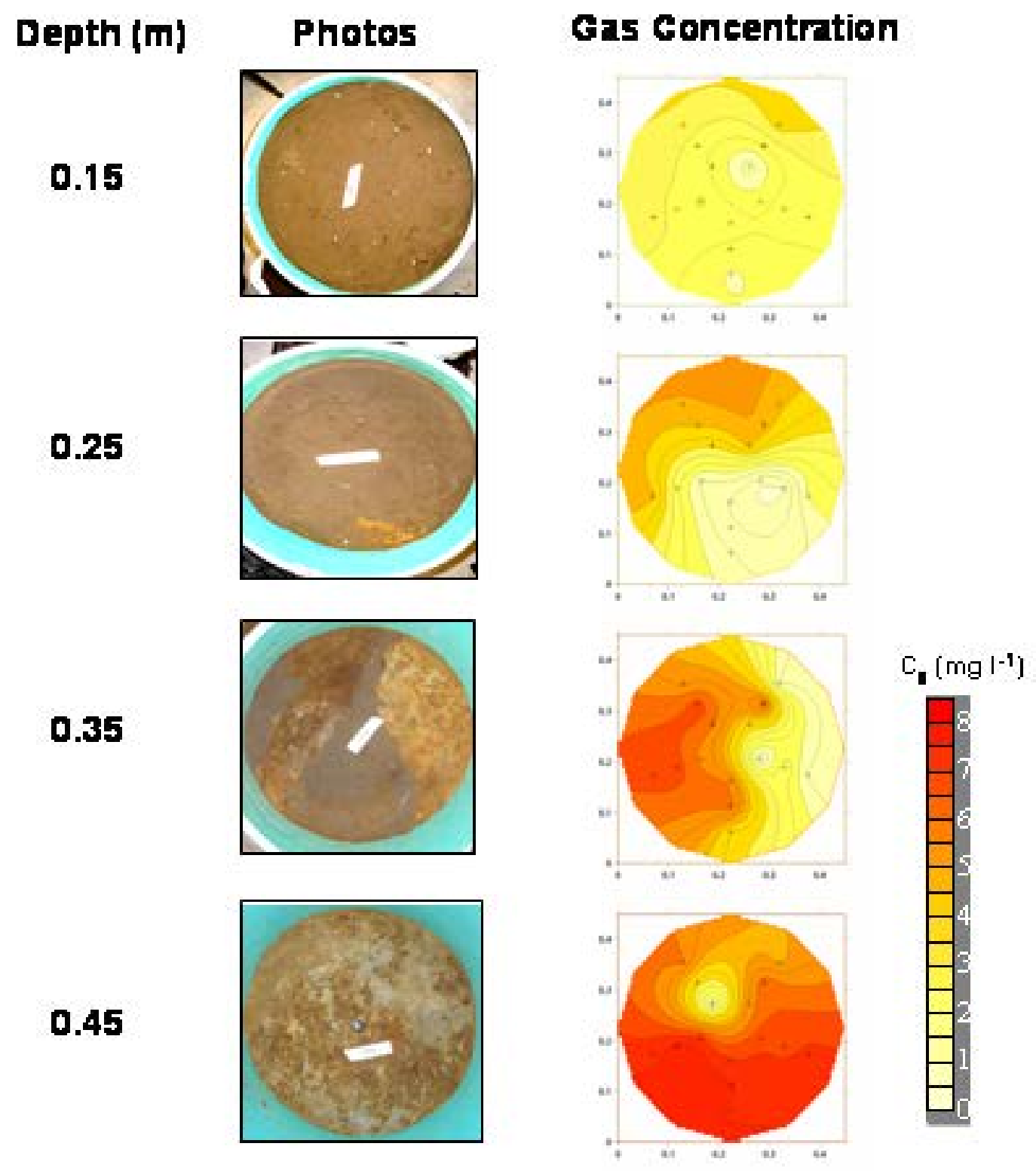

Figure 5. 
SGR
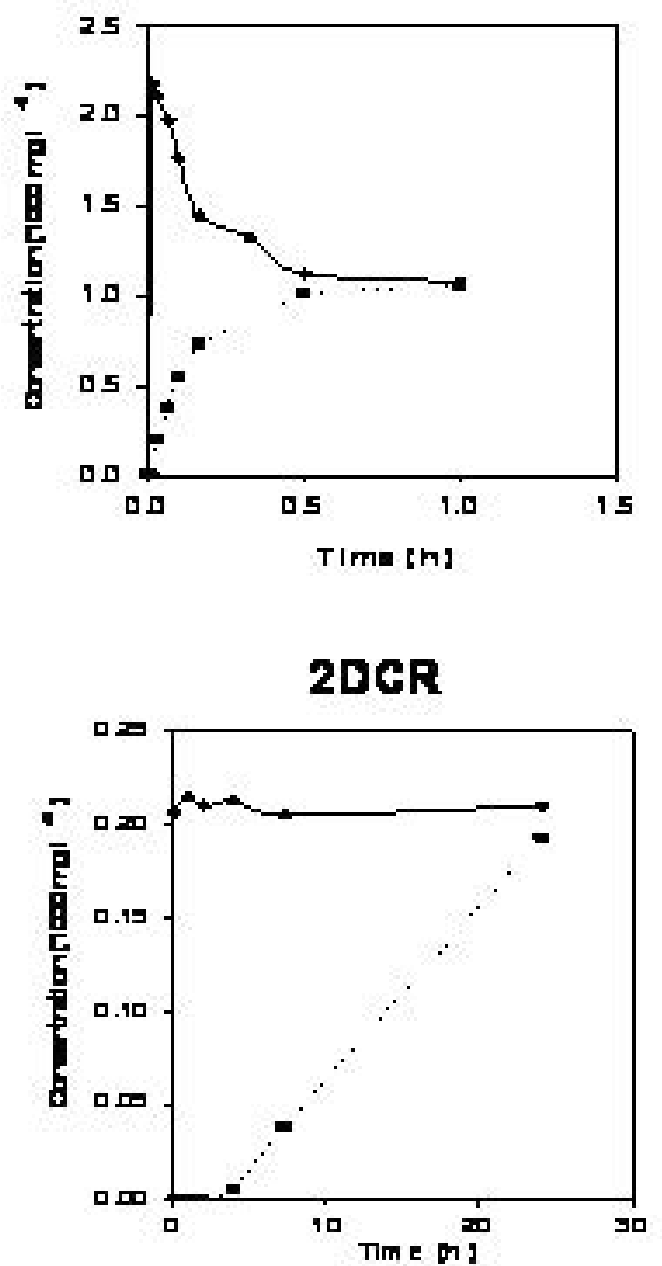

LGR

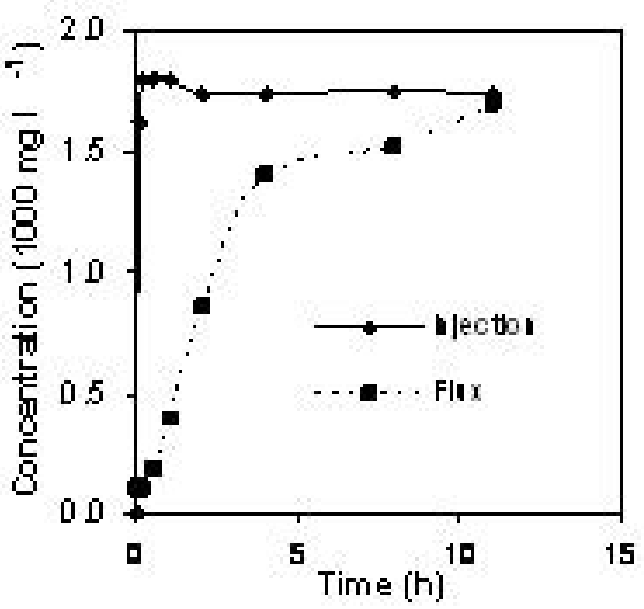

LeI

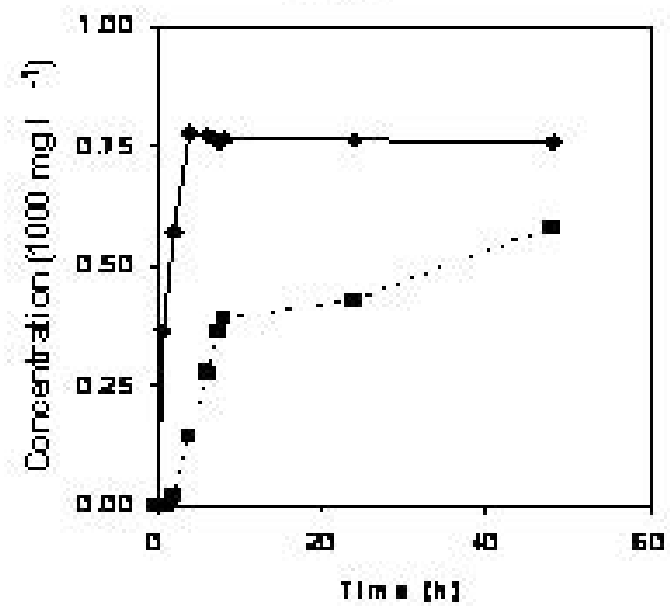

sol

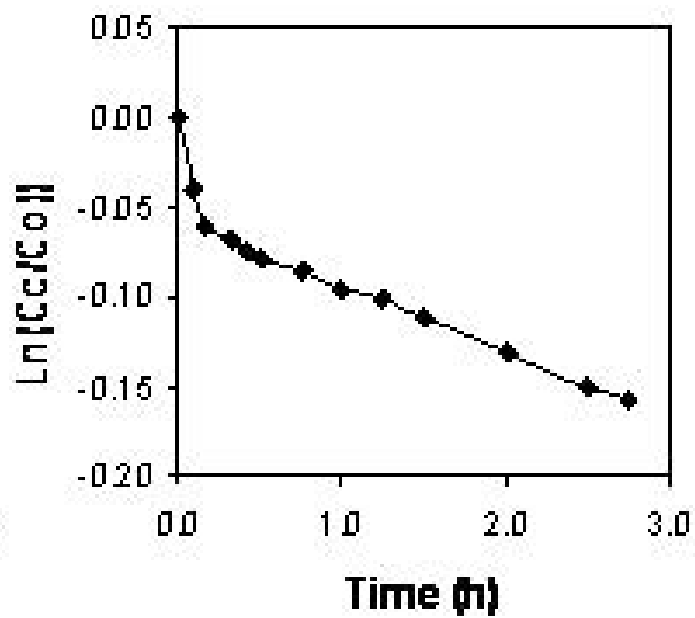

Figure 6. 